\title{
The TACTIC: development and validation of the Tool for Assessing Chest Tube Insertion Competency
}

\author{
Allan Evan Shefrin, MD*; Afshin Khazei, $\mathrm{MD}^{\dagger}$; Geoffrey Robert Hung, MD; Lisa Teres Odendal, $\mathrm{MD}^{\S}$; \\ Adam Cheng, MD"
}

\section{ABSTRACT}

Objectives: Pediatric emergency medicine (PEM) physicians receive little opportunity to practice and perform chest tube insertion. We sought to develop and validate a scoring tool to assess chest tube insertion competency and identify areas where training is required for PEM physicians.

Methods: We developed a 40-point, 20-item (scored 0, 1, or 2) assessment tool entitled the Tool for Assessing Chest Tube Insertion Competency (TACTIC) and studied how PEM physicians and fellows scored when inserting a chest tube into a pork rib model. Participants were scored at baseline and compared to themselves after receiving targeted training using Web-based animations and presentations followed by expert instruction and practice on chest tube insertion task trainers. All insertions were video recorded and reviewed by two blinded reviewers. Eight common videos were reviewed to assess interrater reliability.

Results: The TACTIC demonstrated good interrater reliability with an $r^{2}=0.86$. Our cohort demonstrated a significant improvement in TACTIC scores by taking part in targeted training (precourse TACTIC $=65 \%, 95 \% \mathrm{Cl} 54-76 \mathrm{v}$. postcourse TACTIC $=84 \%, 95 \% \mathrm{Cl} 80-88$ ), highlighting the construct validity of the TACTIC. Individual participants increased their TACTIC scores by an average of $17 \%$.

Conclusions: The TACTIC demonstrates good interrater reliability, content validity, and construct validity in assessing a PEM practitioner's skill inserting chest tubes in a simulated setting.

\section{RÉSUMÉ}

Objectifs: Les médecins en médecine d'urgence pédiatrique (MUP) ne procèdent pas souvent à la pose de drains thoraciques. Aussi avons-nous cherché à élaborer et à valider un instrument de notation visant à évaluer la compétence relative à la pose de drains thoraciques, et à cerner les points faibles qui nécessiteraient une formation chez les médecins en MUP.
Méthode: Nous avons élaboré un instrument d'évaluation portant sur 20 tâches et noté sur 40 points $(0,1,2)$, appelé Tool for Assessing Chest Drain Insertion Competency (TACTIC), et avons étudié les résultats de médecins et de stagiaires en MUP relativement à la pose de drains thoraciques dans un modèle porcin de gril thoracique. Les participants ont été évalués au départ, puis comparés à euxmêmes après une formation ciblée, comportant des animations et des présentations sur le Web, un enseignement théorique donné par des spécialistes et la pratique de la pose de drains thoraciques sur des simulateurs passifs ("task trainers"). Toutes les poses de drain ont été enregistrées sur vidéo, puis examinées par deux examinateurs tenus dans l'ignorance des faits. Huit vidéos courantes ont été revues aux fins d'évaluation de la fiabilité interévaluateurs.

Résultats: L'instrument TACTIC a obtenu de bons résultats au regard de la fiabilité interévaluateurs: $\rho^{2}=0.86$. De son côté, la cohorte a connu une amélioration sensible des résultats, selon la grille TACTIC (avant le cours: 65\%; IC à 95\%: 54-76; après le cours: $84 \%$, IC à 95\%: 80-88), après avoir suivi une formation ciblée, ce qui confirme la validité de construction de l'instrument TACTIC. La note de chacun des participants, selon la grille TACTIC, a augmenté en moyenne de $17 \%$.

Conclusions: Les résultats de l'étude ont démontré que I'instrument TACTIC possédait une bonne fiabilité interévaluateurs, une validité de contenu et une validité de construction, dans l'évaluation de la compétence de praticiens en MUP, relative à la pose de drains thoraciques, en simulation.

$\overline{\text { Keywords: chest tubes, procedural competency, simulation, }}$ task trainers

Pediatric emergency medicine (PEM) physicians must be skilled at safely and efficiently performing potentially life-saving procedures. In the setting of pediatric

From the *Division of Pediatric Emergency Medicine, Children's Hospital of Eastern Ontario, University of Ottawa, Ottawa, ON; †Division of Emergency Medicine, Vancouver General Hospital, University of British Columbia, Vancouver, BC; ‡Canadian Medical Protective Association, Ottawa, ON; §Division of Pediatric Emergency Medicine, Alberta Children's Hospital, Calgary, AB; \|KidSIM-Aspire Simulation Research Program, Section of Emergency Medicine, Alberta Children's Hospital, University of Calgary, Calgary, AB.

Correspondence to: Dr. Allan Evan Shefrin, 401 Smyth Road, Ottawa, ON K1H 8L1; ashefrin@cheo.on.ca.

This article has been peer reviewed 
trauma, they must be able to insert a chest tube for life-threatening cases of pneumothorax, hemothorax, or undifferentiated shock. ${ }^{1}$ In the pediatric emergency department (PED), the opportunity to learn, practice, and perform this skill is rare. ${ }^{2,3}$ Perhaps due to the rarity of the procedure and the acuity of the clinical scenario, emergency medicine practitioners may be more likely to experience adverse outcomes from chest tube placement compared to surgical colleagues. ${ }^{4}$ It is important that we identify the optimal training method and competency assessments for chest tube insertion in the emergency setting.

To acquire and maintain mastery, simulated clinical experiences including task trainers and highfidelity simulators may be used. ${ }^{5-10}$ Although various different chest tube insertion task trainers exist, there is no objective and validated scoring system in the literature to assess chest tube insertion competency. Such a tool could be used to assess a practitioner's skill, identify areas for improvement, or rate on a scale for high-stakes assessment (either in the simulated or real environment). We developed a 40-point scale entitled the Tool for Assessing Chest Tube Insertion Competency (TACTIC) that rates 20 independent tasks in a simulated chest model. This tool was designed to assess a practitioner's chest tube insertion competency and identify areas for future learning.

The purpose of our study was to 1) systematically develop the TACTIC to ensure content validity, 2) assess the TACTIC's interrater reliability when used by multiple raters, 3) examine construct validity by assessing the tool's ability to identify improvement in performance post- versus preinstruction, and 4) differentiate its ability to identify learners of different experience levels.

\section{METHODS}

\section{TACTIC development}

The TACTIC was designed to assess a participant's stepwise performance of tasks necessary to properly insert a chest tube in a simulated trauma setting. The cut-down technique was selected by the lead investigators (A.E.S., A.K., A.C.) as the preferred method of insertion because it is widely available and can be used to treat simple and tension pneumothorax and hemothorax in the trauma setting and other thoracic conditions.
The tasks to be completed during chest tube insertion were identified by reviewing PEM procedural manuals. ${ }^{1,11}$ A comprehensive literature search was conducted to search for published chest tube insertion assessment tools. The tool was initially written and developed by the lead investigators using a 3-point scoring system for each tool item, which was modeled after the clinical performance tool developed by Donoghue and colleagues for pediatric resuscitation assessment. ${ }^{12}$ All tasks were reviewed by the authors and categorized into one of four phases of the TACTIC: 1) preparation, 2) insertion of the chest tube, 3) securing of the tube, and 4) confirmation of placement. Each task was graded as 0 (not done or done so incorrectly as to be dangerous or render the procedure useless), 1 (done, but incorrect technique or functionality limited), or 2 (done correctly). In the event, when a task was an "all or nothing task," scores were either 0 or 2 . These phases could be used to help identify areas where more practice is needed.

The TACTIC was subjected to an iterative review process involving multiple experts in the field of pediatric trauma and acute care with the intention of developing a tool with both content and construct validity. Feedback was incorporated with revision of the tool at each stage. After initial development, a pediatric general surgeon and a pediatric intensive care specialist reviewed it. Following initial revisions, it was presented to the local PEM group at a research symposium. The TACTIC was subsequently revised and piloted on a chest tube insertion task trainer by the lead investigators. Minor modifications were incorporated into the final TACTIC version (Figure 1).

\section{Participants and video-recorded chest tube insertion}

A convenience sample of PEM physicians and trainees from the PED at British Columbia Children's Hospital were enrolled in this study. British Columbia Children's Hospital is a tertiary care pediatric hospital that serves Vancouver, British Columbia, and receives trauma referrals throughout British Columbia and Yukon Territory. Participants were eligible for inclusion if they were a PEM physician or fellow with no specialized training in chest tube insertion beyond residency, fellowship training, and the Advanced Trauma Life Support (ATLS) course (American College of Surgeons, Chicago, IL), which is a training/ 


\begin{tabular}{|c|c|c|c|c|}
\hline \multicolumn{5}{|l|}{ Phase 1: Preparation } \\
\hline Task & $\begin{array}{l}\text { Unable to see } \\
\text { on video/model } \\
\text { error }\end{array}$ & 0 points & 1 point & 2 points \\
\hline $\begin{array}{l}\text { 1. Chest tube } \\
\text { selection* }\end{array}$ & & $\begin{array}{l}\text { Incorrect } \\
\text { size/states does not } \\
\text { know size }\end{array}$ & & Correct size selected \\
\hline $\begin{array}{l}\text { 2. Chest tube } \\
\text { preparation }\end{array}$ & & $\begin{array}{l}\text { Not done/trocar } \\
\text { left in }\end{array}$ & $\begin{array}{l}\text { No trocar, no Kelly } \\
\text { clamp used }\end{array}$ & $\begin{array}{l}1 \text { or } 2 \text { Kelly clamps, } \\
\text { trochar removed }\end{array}$ \\
\hline $\begin{array}{l}\text { 3. Proper } \\
\text { landmarking }{ }^{*}\end{array}$ & & $\begin{array}{l}\text { Any incorrect } \\
\text { position }\end{array}$ & & $\begin{array}{l}\text { 4th or } 5 \text { th intercostal } \\
\text { space, anterior to mid- } \\
\text { axillary line }\end{array}$ \\
\hline 4. Cleaning the site & & Not done & $\begin{array}{l}\text { Cleans with NS or } \\
\text { sterile water only }\end{array}$ & $\begin{array}{l}\text { Cleans site with antiseptic } \\
\text { solution }\end{array}$ \\
\hline 5. Sterile draping & & Not done & & $\begin{array}{l}\text { Appropriately drapes the } \\
\text { area }\end{array}$ \\
\hline $\begin{array}{l}\text { 6. Lidocaine } \\
\text { infiltration? }\end{array}$ & & Not done & $\begin{array}{l}\text { Freezing to } \\
\text { subcutaneous depth }\end{array}$ & $\begin{array}{l}\text { Freezing to subcutaneous } \\
\text { tissues AND intercostal } \\
\text { muscles }\end{array}$ \\
\hline \multicolumn{5}{|c|}{ Phase 2: Insertion of Chest Tube } \\
\hline 7. Skin incision & & Not done & $\begin{array}{l}\text { Incision }<1 \text { finger- } \\
\text { width or }>3 \text { finger- } \\
\text { width }\end{array}$ & 1-3 finger-width incision \\
\hline 8. Tissue dissection & & Not done & Scalpel only & Kelly clamp \\
\hline 9. Finger sweep & & Not done & $\begin{array}{l}\text { Done to improper depth } \\
\text { (too superficial) }\end{array}$ & Done to pleura \\
\hline $\begin{array}{l}\text { 10. Location at } \\
\text { intercostal space* }\end{array}$ & & $\begin{array}{l}\text { Nol done or below } \\
\text { the above rib }\end{array}$ & & $\begin{array}{l}\text { Ahove rib to avoid } \\
\text { ncurovascular bundle }\end{array}$ \\
\hline $\begin{array}{l}\text { 11. Uses finger for } \\
\text { guidance }\end{array}$ & & Not done & & Using index finger \\
\hline 12. Tube placement & & Not done & $\begin{array}{l}\text { Guided without Kelly } \\
\text { clamp }\end{array}$ & Guided with Kelly clamp \\
\hline 13. Tube direction" & & $\begin{array}{l}\text { Placed in any } \\
\text { direction other } \\
\text { than cephalad and } \\
\text { posterior/head }\end{array}$ & & $\begin{array}{l}\text { Cephalad and } \\
\text { posterior/directed to head }\end{array}$ \\
\hline 14. Ports inserted & & Not done & $\begin{array}{l}\text { At least one left outside } \\
\text { of skin }\end{array}$ & All ports inserted \\
\hline \multicolumn{5}{|c|}{ Phase 3: Securing the Tube } \\
\hline $\begin{array}{l}\text { 15. Suturing } \\
\text { technique }\end{array}$ & & Not done & Poor & Good \\
\hline $\begin{array}{l}\text { 16. Roman Sandal } \\
\text { Tie }\end{array}$ & & Not done & Loose/not secure & Tight/well secured \\
\hline 17. Skin suturing & & Not done & Skin not well closed & $\begin{array}{l}\text { Good closure with } \\
\text { approximation }\end{array}$ \\
\hline 18. Suturing time & & $\geq 5$ minutes & $2-5$ minutes & $\leq 2$ minutes \\
\hline 19. Taping/Tegaderm & & Not done & $\begin{array}{l}\text { Inadequate/not covered } \\
\text { completely }\end{array}$ & $\begin{array}{l}\text { Tube well secured and } \\
\text { covered completely }\end{array}$ \\
\hline \multicolumn{5}{|c|}{ Phase 4: Tube Placement Confirmation } \\
\hline $\begin{array}{l}\text { 20. X-ray } \\
\text { confirmation }\end{array}$ & & Not done & & Done/Asked for \\
\hline
\end{tabular}

Total Score $=\quad / 40$

*Verbal cue provided or verbal explanation required

Figure 1. The Tool for Assessing Chest Tube Insertion Competency (TACTIC). NS = normal saline.

practice prerequisite. Participants were excluded if they received any surgical residency training or did not understand English. The British Columbia Children's Hospital Clinical Research Ethics Board approved this study. Informed consent was obtained from all participants.

Participants were asked to perform two videorecorded chest tube insertions in a pork rib model. 
The first insertion was considered their baseline insertion performance ("precourse"). Next, participants took part in targeted chest tube insertion training. A workshop was developed with a Web-based module that incorporated PowerPoint (Microsoft Corporation, Redmond, WA) presentations, animations of the procedure, and a lecture. Then participants received 1-hour hands-on instruction by experts with practice on the chest tube insertion task trainer. The instructor to student ratio in the course was 1:3. Participants were permitted to practice until they felt they had mastered the procedure. On the same day following the course, participants placed another chest tube into the pork model, which was video recorded ("postcourse").

\section{Chest tube insertion task trainer}

The pork rib model used in this study was modeled after a pork rib-based task trainer developed at The Hospital for Sick Children (Toronto, ON) simulation centre (J Pirie, personal communication). It consisted of a halfrack of pork ribs suspended on a metal bowl using plastic wrap to help simulate pleura with an intravenous fluid bag placed underneath the ribs to simulate underlying lung parenchyma. Simulated skin was placed on top, and the model was draped with surgical towels and placed on a table.

\section{Video reviews and rater training}

A study investigator (A.E.S.) performed the video recording, with careful attention given to show only the gloved hands of the participant and the pork rib model. Participants were assigned numeric identifiers to ensure blinding to the video rater. Each participant was presented a scenario of an 8-year-old male who sustained a traumatic pneumothorax that required only insertion of a chest tube. Five verbal prompts were provided at certain points to assess knowledge and skills that could not be seen in the video or assessed with this model. These are highlighted with an asterisk in Figure 1.

Two raters with extensive clinical trauma and education experience in pediatrics were selected to score the video-recorded insertions using the TACTIC. These included our department's quality assurance and improvement director and institution's trauma medical lead. Raters were not involved in the design of the tool or teaching of participants in the chest tube insertion workshop. Both raters received training on how to use the TACTIC prior to assessing study videos. This training consisted of reviewing three trigger videos that were developed by the investigators demonstrating very poor insertion technique, average technique, and excellent technique. The raters were oriented to the TACTIC and asked to rate each of the three trigger videos. The primary investigator (A.E.S.) reviewed the scores for each of the trigger videos with the reviewers to help achieve a common understanding and agreement on scoring for each video. This ensured that our reviewers were calibrated prior to assessing the study videos. Eight videos, including precourse and postcourse videos, were scored using the TACTIC by both reviewers to assess interrater reliability. Each reviewer also scored seven other videos independently using the TACTIC. Video reviewers were blinded to whether the videos were recorded pre- or postcourse and the identity of the participant.

\section{Statistics}

Scores were entered into Excel (Microsoft Corporation) spreadsheets. TACTIC scores from each reviewer on the commonly viewed videos were compared to assess the interrater reliability of the tool. A Pearson correlation coefficient was calculated, and regression analysis was performed to measure the reliability between raters. Pre- and postcourse videos were compared for the participants to assess whether the TACTIC could identify changes in scores after targeted training.

\section{RESULTS}

Eleven participants enrolled in the study, including five attending PEM physicians and six PEM fellows. Twenty-two videos (11 precourse and 11 postcourse) were submitted and rated. PEM attending physicians had an average of 11 years of clinical practice (range 120 years). The PEM fellows included three first-year trainees and three second-year trainees. The PEM attending physicians had inserted an average of 3.2 chest tubes (range 1-5). The first- and second-year trainees had inserted an average of 2.3 (range 0-5) and 4.0 (range 2-5) chest tubes, respectively.

Reviewers were asked to view eight common videos consisting of pre- and postcourse videos. The TACTIC demonstrated good interrater reliability with 
a Pearson correlation coefficient of $r=0.93$. Regression analysis yielded an $r^{2}=0.86$ as shown in Figure 2.

A significant improvement in TACTIC scores for our cohort was observed after targeted training. The mean precourse TACTIC score was $65 \%$ (95\% CI $54-$ 76 ), and the mean postcourse TACTIC score was $84 \%$ (95\% CI 80-88).

A subanalysis of pre- and postcourse scores for fellows showed significant improvement from baseline by taking part in this course $(59 \%$; 95\% CI $43-75 \mathrm{v}$. $82 \%$, 95\% CI 76-88), whereas attending physicians showed a nonsignificant trend toward improvement (73\%; 95\% CI 61-85 v. 88\%, 95\% CI 84-92). These results are shown in Table 1 . These data demonstrated that, although not significantly significant, there is a trend toward attending physicians performing better than fellows, especially at baseline. Although it is expected that attending physicians are more experienced than fellows are, it may be more difficult for the attending physicians to improve as their baseline scores were higher.

Pre- and postcourse TACTIC scores were also analyzed to assess the mean difference for each participant. The mean difference in scores was $17 \%$ (range of 10-55\%; 95\% CI 4-30). Two outliers affect this number, where one participant (an attending physician) showed a decrease of $10 \%$ (scored $100 \%$ on the precourse TACTIC) and one participant (a fellow) increased his score by $55 \%$.

\section{DISCUSSION}

The TACTIC is a reliable tool to assess the insertion of a chest tube into a simulated chest model. The systematic process highlighted its content validity. It showed good interrater reliability and demonstrated construct validity as TACTIC scores improved after targeted training and the interval improvement in scores in fellows was greater than for attending physicians.

Our cohort of PEM physicians and fellows was consistent with previous cohorts that have limited opportunity to practice and perform chest tube insertion. ${ }^{2,3}$ Participants in our study inserted an average of four or fewer chest tubes during their careers. Simulation-based training is required to fill this gap and is approved by both the Royal College of Physicians and Surgeons of Canada and the American Accreditation Council for Graduate Medical Education. ${ }^{13,14}$ Others have demonstrated that simulated experiences are useful adjuncts to fill training gaps. ${ }^{6-8,15-17}$ More evidence is available to suggest that simulated experiences increase procedural knowledge, skill, and behaviours and may improve patient outcomes. ${ }^{5,10,18-21}$

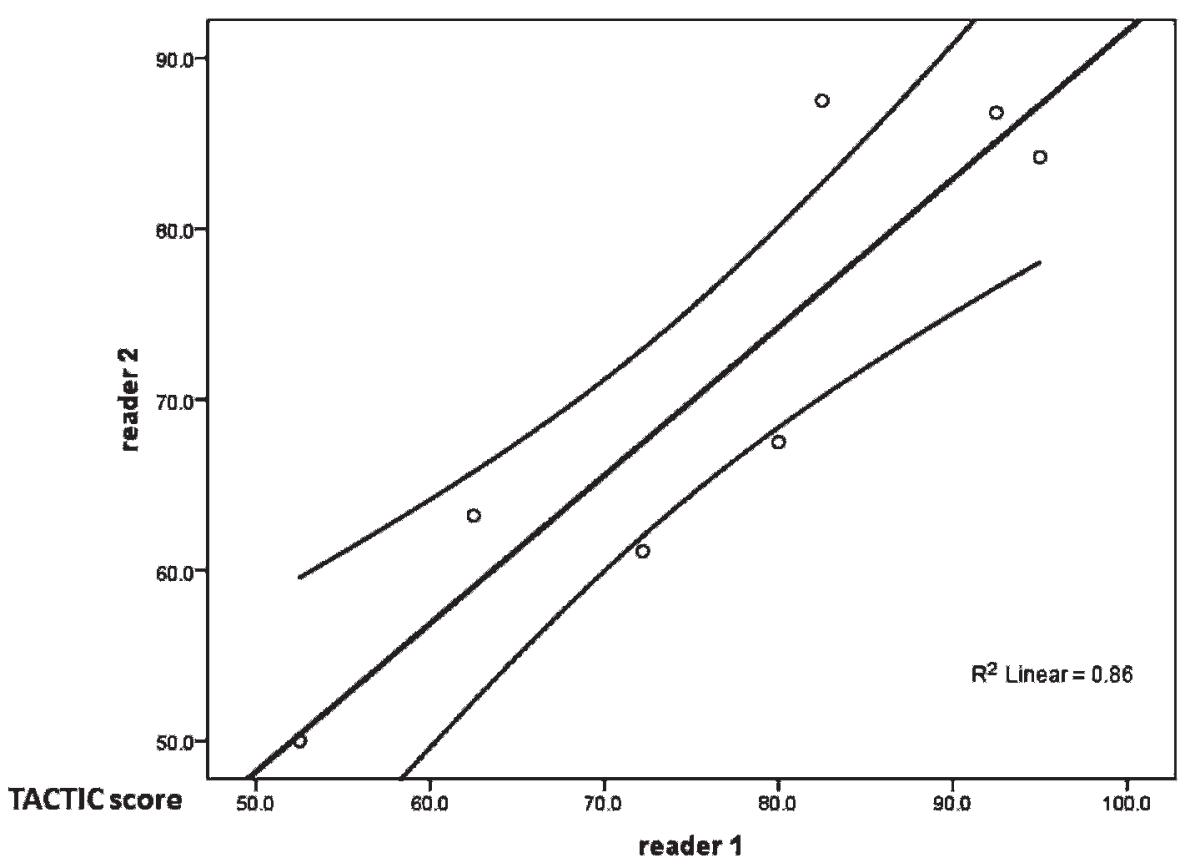

Figure 2. Interrater scatter plot for commonly viewed Tool for Assessing Chest Tube Insertion Competency (TACTIC) videos. 


\begin{tabular}{|c|c|c|c|c|c|c|}
\hline \multirow[b]{2}{*}{ Group } & \multicolumn{3}{|c|}{ Precourse videos } & \multicolumn{3}{|c|}{ Postcourse videos } \\
\hline & Mean (\%) & Range (\%) & $95 \% \mathrm{Cl}$ & Mean (\%) & Range (\%) & $95 \% \mathrm{Cl}$ \\
\hline Fellows & 59 & $23-84$ & $43-75$ & 82 & $71-93$ & $76-88$ \\
\hline Attending physicians & 73 & $58-100$ & $61-85$ & 88 & $84-95$ & $84-92$ \\
\hline
\end{tabular}

The educational intervention, which included both screen-based learning and hands-on learning with feedback, was carefully designed to include several important instructional design features for simulation. A recent meta-analysis by Cook and colleagues described the relative contribution of instructional design features to simulation-based learning. ${ }^{22}$ Several of these design features, including feedback, repetitive practice, cognitive interactivity, individualized learning, and multiple learning strategies, were strategically built into our intervention to ensure optimal learning. Our intervention appears to be more robust than the chest tube insertion training provided in ATLS, where students are not exposed to screen-based learning, have larger student to instructor ratios (less opportunity for feedback), and have less opportunity to practice.

Our study assumed that participation in a targeted simulation-based procedural training program increases skill, comfort, and knowledge. Our results supported construct validity of the tool for this population of learners: the participants showed a significant increase in TACTIC scores, and the increase in TACTIC scores was greater for fellows than for staff. This highlights the capability of the TACTIC to be able to identify improvement and differentiate the abilities among health care professionals with varying levels of experience.

The TACTIC also has the ability to highlight specific participant areas that need to be addressed to improve competency. As it is divided into four phases-1) preparation, 2) insertion of the chest tube, 3) securing the tube, and 4) confirmation of placement-the TACTIC allows for identification of troublesome areas for a learner or cohort. The phase where our cohort showed most difficulty was phase 3 , securing the tube. This may be attributable to textbooks not elaborating on tube securement. Although other tasks are explained in great detail, the learner is directed to secure the tube by stitching the tube in place, without elaboration. ${ }^{1,23}$ The TACTIC identifies this area requiring work and allows educators to target further training.

Medical education is moving from an experiential learning model (where a learner is expected to perform a set amount of procedures) to a competency-based assessment model. One of the inherent challenges is developing validated assessment tools to measure performance. The iterative design, video review, and performance of our tool are similar to those of other validated assessment tools used in simulation curricula. ${ }^{12,24-26}$ Some tools may be tested at baseline and after a period of practice, like the TACTIC, ${ }^{12,27}$ or measured against clinical experience..$^{24,26,28}$ With a plethora of different clinical skills, procedures, and ways to perform each, the development of these tools is challenging. Checklists that use a 2-point scoring (e.g., yes or no) can be helpful, but the simple performance of a task may not yield any information on the quality of the performance. Some, like the TACTIC, incorporate a third option where one can attribute some assessment of quality value to the task. ${ }^{12,27,28}$ Although it is clear that scoring poorly on a checklist likely means that the task is performed poorly, determining the score at which the procedure is performed "well enough" or "excellently" can be challenging. More work is needed with the TACTIC to determine what scores constitute a competent practitioner versus an expert.

Our study was limited by several factors. It was conducted at a single centre with a small cohort. It would be interesting to see how the TACTIC performs with a larger cohort including other centres. It is not clear how the TACTIC would perform in a population with more experience placing chest tubes, such as general emergency medicine. This represents a future angle to study the TACTIC. It would be of benefit to assess if skills and knowledge persisted into longer time frames, perhaps 3 and 6 months after the course, and whether the TACTIC appropriately detects these differences. Further studies can determine when retraining would be needed. This study 
took place in a simulated environment and on a simulated chest model. It may be difficult to extrapolate our data to a real-life clinical scenario where other factors might be at play. Until further studies are available in a real-life clinical scenario, the TACTIC should be applied to educational uses only. In PEM, the rarity of opportunities for chest tube insertion in live patients will likely prohibit a comprehensive study of the TACTIC in live procedures. The timing of the postcourse TACTIC may be brought into question. Postcourse chest tube insertions were video recorded on the day of the course following participation. This timing was selected because the performance was anticipated to be the best, highlighting the TACTIC's ability to assess improvement over baseline. Reassessing the TACTIC at a later interval might provide information regarding skill retention or loss and the TACTIC's ability to detect these changes.

\section{CONCLUSION}

We systematically developed and evaluated a chest tube insertion competency assessment tool entitled the TACTIC, which demonstrated good interrater reliability, content validity, and construct validity when used for assessing PEM fellows and attending staff physicians in a simulated trauma environment.

Competing interests: None declared.

\section{REFERENCES}

1. Mikrogianakis A, Valani R, Cheng A. The Hospital for Sick Children manual of pediatric trauma. 1st ed. Philadelphia: Wolter Kluwer/Lippincott Williams \& Wilkins; 2008.

2. Al-Eissa M, Chu S, Lynch T, et al. Self-reported experience and competence in core procedures among Canadian pediatric emergency medicine fellowship trainees. CFEM 2008;10:533-8.

3. Paul RI, King L. Technical skills experiences in pediatric emergency medicine fellowship programs. Pediatr Emerg Care 1996;12:10-2, doi:10.1097/00006565-199602000-00003.

4. Ball CG, Lord J, Laupland KB, et al. Chest tube complications: how well are we training our residents? Can 7 Surg 2007;50:450-8.

5. Cook D, Hatala R, Brydges R, et al. Technology-enhanced simulation for health professions education: a systematic review and meta-analysis. $7 A M A$ 2011;306:977.

6. Issenberg SB. The scope of simulation-based healthcare education. Simul Healthc 2006;1:203-8, doi:10.1097/01. SIH.0000246607.36504.5a.

7. Bond WF, Spillane L. The use of simulation for emergency medicine resident assessment. Acad Emerg Med 2002;9:12959, doi:10.1197/aemj.9.11.1295.
8. Lammers RL, Davenport M, Korley F, et al. Teaching and assessing procedural skills using simulation: metrics and methodology. Acad Emerg Med 2008;15:1079-87, doi:10. 1111/j.1553-2712.2008.00233.x.

9. Nestel D, Groom J, Eikeland-Husebo S, et al. Simulation for learning and teaching procedural skills: the state of the science. Simul Healthc 2011;6(7 Suppl):S10-3, doi:10.1097/ SIH.0b013e318227ce96.

10. Sanchez LD, Delapena J, Kelly SP, et al. Procedure lab used to improve confidence in the performance of rarely performed procedures. Eur 7 Emerg Med 2006;13:29-31, doi:10.1097/00063110-200602000-00007.

11. Ruddy RM. Insertion of a chest tube. In: Fleisher GR, Ludwig S, Henretig FM, et al. Textbook of pediatric emergency medicine. 5th ed. Philadelphia: Lippincott Williams and Wilkins; 2006. p. 1904.

12. Donoghue AM, Ventre K, Boulet J, et al. Design, implementation, and psychometric analysis of a scoring instrument for simulated pediatric resuscitation: a report from the EXPRESS pediatric investigators. Simul Healthc 2011;6:71-7, doi:10.1097/SIH.0b013e31820c44da.

13. Royal College of Physicians and Surgeons of Canada. Objectives of training in pediatric emergency medicine. Available at: http://rcpsc.medical.org/information/index.php?specialty $=462 \&$ submit $=$ Select (accessed August 1, 2013).

14. American Accreditation Council for Graduate Medical Education. Emergency medicine guidleines. Available at: http:// www.acgme.org/acWebsite/RRC_110/110_guidelines.asp\#res (accessed August 1, 2013).

15. Nargozian CD. Simulation and airway-management training. Curr Opin Anesthesiol 2004;17:511-2, doi:10.1097/ 00001503-200412000-00011.

16. Vozenilek J, Huff JS, Reznek M, et al. See one, do one, teach one: advanced technology in medical education. Acad Emerg Med 2004;11:1149-54, doi:10.1111/j.1553-2712.2004.tb00 698.x.

17. Dawson S. Procedural simulation: a primer. 7 Vasc Interv Radiol 2006;17:205-13, doi:10.1097/01.RVI.0000194871. 97225.CA.

18. Niemi-Murola L, Helenius I, Turunen J, et al. Graduating medical students and emergency procedure skill teaching in Finland-does a clinical skills centre make the difference? Med Teach 2007;29:821-6, doi:10.1080/01421590701601568.

19. Nishisaki A, Hales R, Biagas K, et al. A multi-institutional high-fidelity simulation "boot camp" orientation and training program for first year pediatric critical care fellows. Pediatr Crit Care Med 2009;10:157-62, doi:10.1097/ PCC.0b013e3181956d29.

20. van der Vlugt TM, Harter PM. Teaching procedural skills to medical students: one institution's experience with an emergency procedures course. Ann Emerg Med 2002;40:419, doi:10.1067/mem.2002.125613.

21. House AK, House J. Improving basic surgical skills for final year medical students: the value of a rural weekend. Aust NZ7 Surg 2000;70:344-7, doi:10.1046/j.1440-1622.2000.01824.x.

22. Cook D, Hamstra S, Brydges R, et al. Comparative effectiveness of instructional design features in simulationbased education: systematic review and meta-analysis. Med Teach 2013;35:e867, doi:10.3109/0142159X.2012.714886. 
23. Fleisher GR, Ludwig S, editors. Textbook of emergency medicine. 5th ed. Philadelphia: Lippincott Williams \& Wilkins; 2005.

24. Brett-Fleegler MB, Vinci RJ, Weiner DL, et al. A simulatorbased tool that assesses pediatric resident resuscitation competency. Pediatrics 2008;121:e597, doi:10.1542/peds. 2005-1259.

25. Ventre KM, Collingridge DS, DeCarlo DM, et al. Performance of a consensus scoring algorithm for assessing pediatric advanced life support competency using a computer screen-based simulator. Pediatr Crit Care Med 2009;10: 623-35, doi:10.1097/PCC.0b013e3181b00ee4.

26. Huang GC, Newman LR, Schwartzstein RM, et al. Procedural competence in internal medicine residents: validity of a central venous catheter insertion assessment instrument. Acad Med 2009;84:1127-34, doi:10.1097/ ACM.0b013e3181acf491.

27. Friedman ZMD, Katznelson RMD, Devito IMD, et al. Objective assessment of manual skills and proficiency in performing epidural anesthesia-video-assisted validation. Reg Anesth Pain Med 2006;31:304-10, doi:10.1097/00115550200607000-00005.

28. Friedman ZMD, Siddiqui NMD, Katznelson RMD, et al. Experience is not enough: repeated breaches in epidural anesthesia aseptic technique by novice operators despite improved skill. Anesthesiology 2008;108:914-20, doi:10.1097/ ALN.0b013e31816bbdb6. 